\section{SCIENCE AND THE CIVIL SERVICE}

THE great technical developments of the nineteenth century, which were due in a large measure to the influence and progress of science, have undoubtedly introduced not only a great transformation in the internal affairs of the country, but also an altered outlook in the external relations of the State. In consequence, many and extensive have been the changes gradually brought about, during the past century, in the duties and responsibilities of the Civil Service. Every Government Department has been affected to some extent; in some of them there have come into existence innovations which are of a very far-reaching character. The outstanding feature of this evolution is that the work of Government Departments has to-day entirely ceased to be of a purely administrative order, whether it be in relation to legislative measures referred thereto for preparation, revision, or criticism, or to the operations conducted therein, or to the sphere of human activity superintended, controlled, or managed thereby. The business of every Government Department is to-day to some extent technical or scientific; in the case of some Departments the administrative aspect predominates; in others it is the technical or scientific aspect that plays the more important rôle.

What, then, has the State done to ensure that the personnel of the Civil Service, through whom its responsibilities must be largely exercised, shall be properly qualified and equipped for dealing, under present-day conditions, with the social, industrial, and commercial problems which must come before it for legislative, executive, or other action?

One important step certainly has been taken in relation to this matter: it has been definitely laid down that candidates for the Civil Service shall, before appointment, be required to undergo some test as to their knowledge and capacity. To give effect to this decision the Civil Service Commission was, by an Order in Council dated May 2I, I 855 , appointed to organise a system of examination; the Commission continues to be charged to the present day with the duty of providing suitable candidates for the public services. In 1870 the principle of open competition was introduced for the purpose of filling certain specified situations in the Civil Service, without, however, entirely abolishing "patronage" appointments. Afterwards, in 1876 , the clerical establishment of the Civil Service was divided into a higher and a lower division; in 1890 the name "lower division " was altered to "second division," and a provision introduced making it possible for a "second division" clerk to be promoted to a higher division clerkship. It is the clerical establishments of the Civil Service which have alone received attention in the foregoing legislation.

Obviously, it is on the coriplete success of the competitive examination scheme in force that the welfare of the Civil Service, and, therefore, the NO. 2545, VOL. IOI] protection of the public interest, must depend. It is here that a serious failure has occurred; the open competitive scheme has not been an entire success; it has been productive of a very unfortunate result.. The system of marking adopted in the examination favoured candidates whose education consisted largely in the learning of ancient Greece and Rome, and handicapped those whose forte was science.

Furthermore, in practically every case the officials who have in recent years received "patronage" appointments in the higher division of the Civil Service are men whose education and training have been identical in character with those of Civil Servants entering the Service by open competition. In consequence, at the present day the highest administrative posts in nearly every Department are monopolised by men whose learning is entirely literary. Further, the technical officers - that is, those in whose education science has played the preponderating róle, and on whose skill and knowledge the welfare of many of the public services very largely depends-are almost entirely excluded from a share in the important administrative posts; needless to say, much to the injury of the public services.

Could it be shown that a purely classical or literary education really tends to develop or to produce administrative talent in an individual superior to that which can be obtained by means of a scientific education and technical training, as is sometimes claimed, there might indeed be some excuse for the retention of the principle of selection adopted; but there is none in actual fact. There exists on the contrary, abundant evidence to prove conclusively that administrative talent is no exclusive privilege or quality of those who have received a purely classical or literary education: the names are familiar, in wide circles, to high and low, of men who have proved themselves capable administrators of the highest order; men, possessing the capacity of a Cromer or of a Kitchener, in whose education instruction in science also occupied a very prominent place; men whose early years were, too, spent in technical spheres.

The opinion has been gaining ground for some time past that the administrative system of Government Departments is unsatisfactory. The extracts from the reports of the Exchequer and Audit Department published from time to time, wherein publicity is given to the defects in the administrative arrangements in connection with the public services, have provided, in relation to such matters, authentic evidence tending to confirm, in the public mind, the unfavourable opinions that prevail so widely as to the unbusinesslike methods of the Civil Service and the general lack of capacity shown by a large majority of its members. Other authentic evidence is available - some recorded, some not; some public property, some not-which provides an indication that scientific knowledge and technical experience are held in disrepute in many, happily not in all, Government Departments; and, further, that the profes- 
sional opinions of technical officers too frequently are not given the due weight which they deserve. Science has done much for the Civil Service; it has not, in return, received the recognition which it merits.

The question arises: How can the defects and abuses known to exist in the Civil Service be best corrected? Remedies there are, some of which have been made public. Such remedies are not competitive inter se: they can be applied concurrently, and are capable both of promoting the welfare of the Civil Service and at the same time of adequately protecting the public interest. The report of Sir J. J. Thomson's Committee on the position of natural science in the educational system of Great Britain (Cd. 90II) contains two important recommendations having these objects in view, viz. (a) that all candidates for the competitive examination for the Home and Indian Civil Services should supply evidence of a continuous training in science extending over several years; and $(b)$ that many posts in the public services should be filled by men selected, not by the ordinary competitive examination, but, at a riper age, on the ground of high scientific qualifications and professional experience.

In view of the present organisation of the Civil Service, it is very certain that the adoption of the first of the foregoing recommendations alone, as a solitary and isolated measure of reform, will not cure the defects known to exist in the Service. The scheme will do little to provide the Civil Service with a sufficient number of men of high scientific attainments and proficient technical knowledge capable of administering the affairs of a modern State in the spirit of progressive knowledge; it will not remove the schism between the administrative and technical staffs of the same Department, a schism which, unfortunately, exists in some Departments to-day.

As regards the second of the above recommendations, presumably the intention is that the men of riper years selected on the ground of professional experience shall fill some of the high administrative posts in the higher division. If this is so, the recommendation is an admirable one and. worthy of immediate adoption. But the question arises whether the State will provide remuneration at a rate high enough to secure for the public services men of sufficiently good abilities. Unless it does so, nothing will be gained by the adoption of the recommendation.

A Government penșion under the special provisions contained in section iv. of the Superannuation Act, 1859 (22 Vict., c. 26)-i.e. one calculated at a higher rate than the ordinary scalemight possibly, in some instances, have been considered by candidates a sufficient compensation for the lower rates of salary prevailing in the Civil Service as compared with those paid by private employers and public corporations. Brit this feature of the Government pension scheme, provided originally to meet the cases of the kind now under consideration, has ceased to exist: the section of the Act of 1859 in question was reNO. 2545 , VOL. IOI] pealed by section v. of the Superannuation Act, I9I4 ( 4 \& 5 Geo. V., c. 86 ).

The only effective remedy for curing the ills from which the Civil Service is suffering at the present time consists in a root-and-branch reform, a reform involving the re-fashioning of its entire framework and fabric. No dangerous or expensive experiments are necessary for the purpose of "trying out" and "proving in" a new organisation: a model well worthy of imitation exists in the Swedish Civil: Service, with its administrative boards. This model could easily be adapted to meet the requirements of this country; the system of administrative boards would provide a means for utilising to the best advantage the existing administrative and technical officers in the Civil Service by associating with them men of large business and professional experience drawn from outside the public services. A reorganisation on the lines here suggested would naturally bring in its train the recognition of the necessity for a more widespread knowledge of science in the Civil Service. Simultaneously, effect could be given to the recommendation regarding the appointment, to permanent posts of the higher division, of men of professional experience as recommended by Sir J. J. Thomson's Committee. Finally, with the advent of the administrative boards would disappear the methods of administration based on the despot's maxim, Divide et impera, methods which continue to have a vogue in certain Departments. Such methods, it is scarcely necessary to point out, are extremely wasteful, and can have no place in any régime which relies for its prosperity and efficiency on science.

\section{THE EARLY HISTORY OF THE SOLAR SYSTEM.}

A COMMON feature of the older theories of the A origin of the solar system is that they all suppose it to have been derived from a more or less symmetrical rotating nebula in a gaseous or quasi-gaseous state. By some process, the details of which differ in different theories, this mass is supposed to have condensed locally to form the sun and planets. A recent paper by Jeans has indicated a way of examining whether such condensation is possible. Viscosity is insufficient to cause a mass so large as the primitive nebula to rotate like a rigid body; each part would revolve practically independently around the centre under gravity, and the matter near any point, on account of the differences between the velocities of different parts, would be in a state of rotation with an angular velocity different from that of its revolution as a whole. It is, however, easily shown that the two are of the same order of magnitude. Now a mass cannot condense locally unless the density is so great that mutual gravitation is enough to balance the centrifugal force due to the rotation, and this indicates that, before condensation started at distance $r$ from the centre, the density there must have been at least com- 